\title{
INJECTION OF THE RETINAL VASCULAR SYSTEM IN THE ENUCLEATED EYE IN DIABETIC RETINOPATHY*
}

BY

\author{
NOKMAN ASHTON \\ From the Department of Pathology, Institute \\ of Ophthalmology, London
}

In the course of our studies in diabetic retinopathy, a preliminary report of which was recently issued in this Journal (Ashton, 1949), many methods of demonstrating the retinal vasculature have been tried, among which in jection of the retinal capillaries in the excised eye with a variety of dyes and plastic materials has been attempted and is still being investigated. So far the use of Indian Ink has been found extremely effective and during the course of our work Michaelson and Steedman (1949) published a similar method for injecting the freshly enucleated eye and they have indicated the potentialities of this technique in anatomical and pathological studies. It is thought, therefore, that the publication of photographs of the injected retina from a case of advanced diabetic retinopathy would be of timely interest. Our method varies in detail from that of Michaelson and Steedman.

\section{METHOD}

The technique may be applied to either fresh or post mortem material. In order to prevent the fixation of blood in the capillaries the whole eye was not placed in formol saline as adrocated by Michaelson and Steedman. The free end of the optic nerve is dipped in 10 per cent. formol saline for a few minutes and is then cut transversely with a sharp scalpel to give a clean flat surface. The globe is held inverted in an iris diaphragm and placed under a stereoscopic dissecting microscope. The cut surface of the nerve is illuminated with a point source of light and the pouting central vessels may be clearly seen in the majority of cases. A fine glass capillary canula, bent at an angle of about $120^{\circ}$, is drawn from a glass tube of $\overline{\mathrm{mmm}}$. internal bore and $3 \frac{1}{2}-4 \mathrm{in}$. in length. The capillary canula, bent at an angle of about $120^{\circ}$, is drawn from a and cut to approximate to the required size. The canula is now attached to the suction tap of an electric pump (Edward's Rotary Vacuum Pump and Compressor) and distilled water is sucked into the tube which holds about 2 ccs. This method of filling

\footnotetext{
* Received for publication, September 27, 1949.
} 
ensures that no particles enter the tube and block the capillary at the time of injection. The canula is now attached to the pressure tap of the same pump, adjusted to give a pressure of about $10 \mathrm{lbs}$. and the capillary tube is inserted into the vein or artery. An assistant works the motor switch, thus the operator has only to hold the canula in position. The irrigation of vessels with water lyses the red cells and opens up channels which might otherwise remain blocked. The water is allowed to remain in the vessels for 5-10 minutes for maximum haemolysation to take place and then more distilled water is run through. The vessels are then irrigated with $\mathbf{1 0}$ per cent. formol saline to fix them in the distended position. The canula is now charged with Indian Ink as above, and the final injection made. The injected eye is placed in 10 per cent. formol saline for 12 hours. The retina is then removed and mounted in a glass sphere, as described in our preliminary report, except that the optic nerve head is now included with the retina by cutting posteriorly with a sharp spoon, and examined under the microscope and photographed for record purposes.

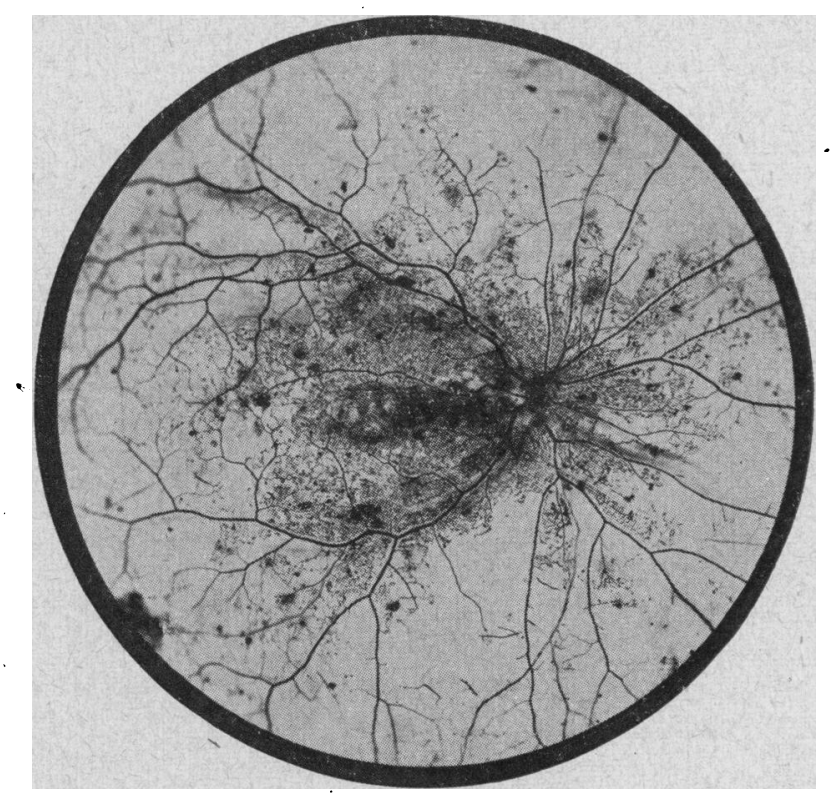

FIG. 1.

Left retina mounted in a glass sphere after injection of the vessels with Indian ink. Shows a Stage 11 I diabetic retinopathy. Scattered haemorrhages and many thousands of micro-aneurysms can be seen. $\times 4^{\circ} 5$. 


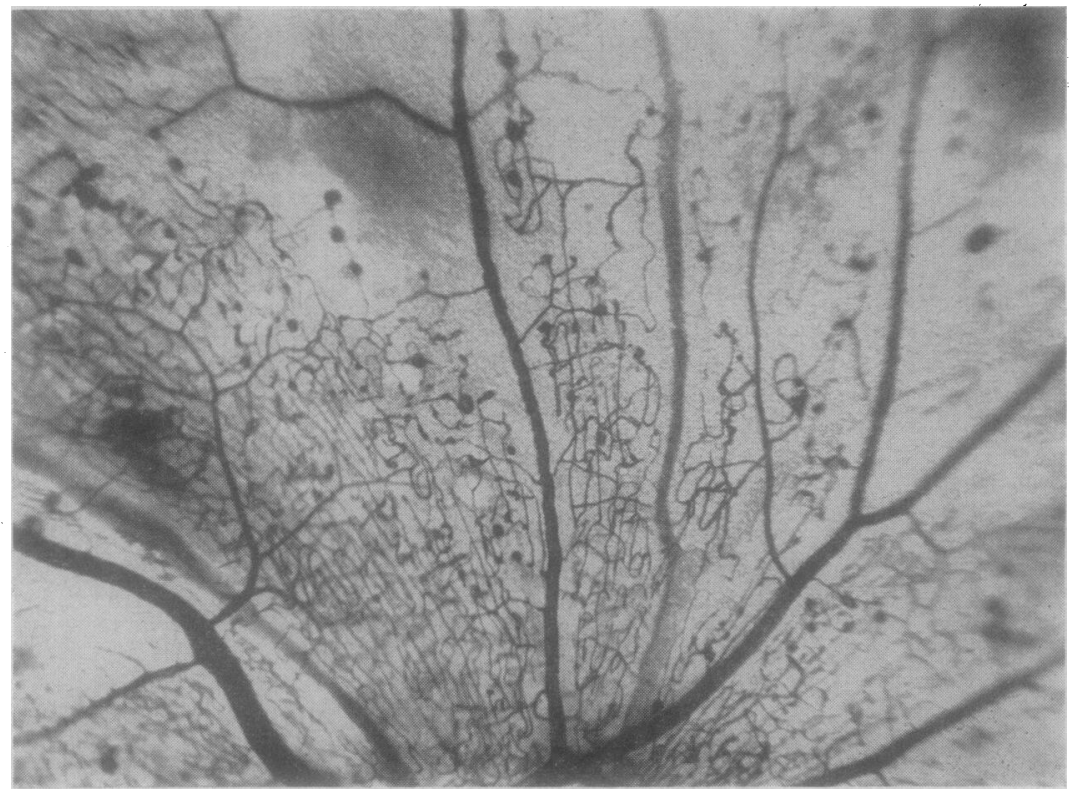

FIG. 2.

Higher magnification of retina shown in Fig. 1. Note the large number of aneurysms. $\times 27 \cdot 5$.

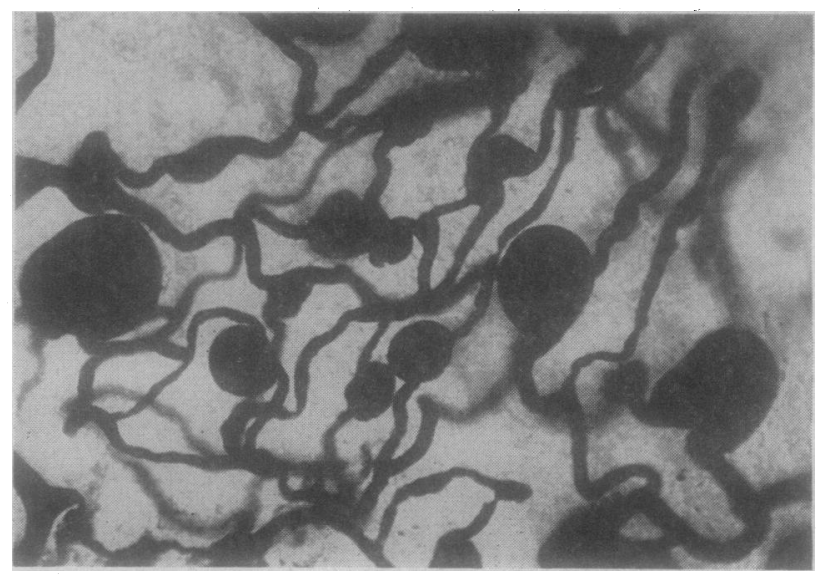

Injected retina showing many aneurysms, beading, looping and irregularity of the capillaries. $\times 200$. 
The case here shown is the retina from an injected right eye taken at post mortem from a female aged 71 who had suffered from diabetes for twenty-six years. There is a Stage III diabetic retinopathy with micro-aneurysms, irregular haemorrhages, macular and punctate exudates. Although the injection is not as complete as we have obtained in freshly excised eyes, it is satisfactory for a post mortem specimen and the picture clearly shows some thousands of micro-aneurysms. Beading, localised dilatations and looping of the vessels and multiple haemorrhages can be seen. It is believed that it has not previously been realised how surprisingly numerous micro-aneurysms are and the picture is a depressing one for one wonders how it can ever be possible to reverse such a gross and widespread process by the administration of drugs or the control of diet. At best we can only hope to prevent the development of such lesions or, once the condition is established, to attempt to control the haemorrhages.

I am indebted to Dr. Peter Hansell for the photographs.

\section{REFERENCES}

Ashton, Norman (1949).-Brit. J. Ophthal., 53, 407.

Michaelson, J. C. and Steedman, H. G. (1949).-Ibid., 33, 376.

\section{CONVERGENCE DEFICIENCY*}

An investigation into the results of treatment

BY

\section{A. Mellick}

GLASGOW

Over the period of twelve months which covered the present investigation, 88 patients attending the out-patient department of the Glasgow Eye Infirmary manifested the subjective and objective features of convergence deficiency. 'Their ages ranged from 14 to 50 years, 32 being below 20 years of age, 37 in the third decade, 15 in the fourth decade, and 4 in the fifth decade. Of the 88 patients, 51 were females, and 37 males. Thirty-seven cases were emmetropic ; in 43 hypermetropia or hypermetropic astigmatism was present, and in 8 myopia or myopic astigmatism.

Fifteen of the 88 cases were considered unsuitable for orthoptic treatment. Of these, 12 suffered from so pronounced a degree of neurosis, that the immediate consideration was the treatment of 


\section{RICHARD SEEFELDER}

PROF. R. SeEFELDER, who died on October 12, 1949, was born in Bavaria in 1875, graduated at Munich and started his early medical career as a regular army medical officer in the Saxon army. In 1904 he was seconded to the University Eye Hospital, Leipzig, then under Sattler. His appointment to the chair of Ophthalmology at Innsbruck University, as successor to. Meller, followed his discharge from the army after the first world war in 1919. He stayed at Innsbruck for the rest of his life.

In this country, as indeed almost everywhere in the ophthalmo. logical world, Seefelder was best known as the co-author and editor with Bach of the "Atlas of the Development of the Human Eye". Publishod in 1911, this monumental and most beautifully illustrated work became a classic. In later years he covered the same field, together with that of developmental abnormalities, in two large chapters of Brückner-Schieck's "Kurzes Handbuch der Ophthalmologie" (1931). But his interests were by no means confined to this semi-academic approach to ophthalmology. In his early days at Leipzig he made a valuable contribution to the aetiology and clinical study of jequirity ophthalmia. In the late '20s and early ' 30 s of this century he was amongst the first to establish recognition for Boeck's sarcoidosis as a separate entity in the mass of aetiologically ill-defined chronic affections of the outer and inner eye which, so long as they were not definitely syphilitic, were all somewhat summarily attributed to tuberculosis. At congressional meetings he was a clear, refreshingly uncomplicated, and straightforward speaker.

$$
\text { P. L. K. }
$$

\section{NOTES}

Lectures

A Course of Three Public Lectures entitled "Visual Physiology" will be given by Dr. L. C. Thomson, Ph.D., M.B., B.S., Vision Research Unit, Medical Research Council, Institute of Ophthalmology, on Tuesdays at 5-15 p.m., at the Physiology. Theatre, Gower Street, W.C.1.

Syllabus:-February 7, What are the problems?; February 14, Colour Vision and the Brightness Mechanism; February 21, Foveal Tritanopia.

\section{Erratum}

B. J. O., Vol. XXXIV, January, 1950. P. 38, para. 2, line 13, for: "The capillary canula, bent at an angle of about $120^{\circ}$, is drawn from a and cut to approximate to the required size", read "The capillary is compared under the microscope with the central vessels and cut to approximate to the required size". 